\title{
A presidential and personal reflection on SASOP during the past decade
}

\begin{abstract}
I became involved with the South African Society of Psychiatrists (SASOP) on the national front in 2002, when I happened to be the chair of the Free State subgroup and was appointed as the convener of the 2004 congress. In the decade that has passed, and as my involvement with SASOP has grown, I have been witness to the evolution of our Society to where it finds itself in 2012 - proudly celebrating 60 years of psychiatry in South Africa.
\end{abstract}

My initial introduction to SASOP was as a registrar in Bloemfontein, and very much by default. At the time, the SASOP presidency was rotated between the different academic heads of departments our head had his tenure during my time as a registrar. Subgroup meetings were relatively formal, but there was some sense of matters being addressed on a national level. The meetings were attended by all members of the department, as well as the small number of practising private psychiatrists. I continued my involvement when I left the department at the end of 1996 to establish a private practice in Bloemfontein.

As the convener of the 2004 national congress, I was required to attend all meetings of the so-called 'SASOP National Executive', and my regular trips to Johannesburg commenced. My introduction to SASOP on a national level coincided with the presidency of the first private psychiatrist to hold office, and a substantial change in focus for the Society. Dr Eugene Allers impressed, as being a driven and passionate psychiatrist who was armed with an infinitesimal knowledge of, inter alia, the legal aspects affecting the practice of psychiatry, especially pertaining to private practice. It was during this year that the contentious Mental Health Care Act (MHCA) of 2002 saw the light - legislation that was to be much debated and worked on by the SASOP National Executive for the entire ensuing decade. Investigations also commenced into changing SASOP to a Section 21 company.

The African Association of Psychiatrists and Allied Disciplines (AAPAP) was officially constituted at the World Congress of Psychiatry in Yokohama, Japan, in 2002. SASOP has been an active member of this group over the last decade. In 2003, the representative Private Psychiatrists of South Africa (PPSA) group was already becoming increasingly active, and meetings were being held with bodies such as the Board of Healthcare Funders (BHF), the Life Offices' Association $(\mathrm{LOA})$ and the like. It was clear that the issues surrounding medical boarding and disability were becoming critical and needed to be formalised. The need for standard treatment guidelines was becoming apparent. Both of these matters would ultimately affect private and state-employed psychiatrists and SASOP needed to take the lead in determining the way forward.
Under the leadership of Dr Allers, the Anti-Stigma initiative continued to take shape, and work began with the consumer groups to bring about parity of treatment for patients suffering from mental disorders. A significant amount of work was done on a White Paper and representations made to the Health Portfolio Committee in Parliament. Considering the massive amount of change (and accompanying red tape) that has ensued in benefits for patients in psychiatry, this work formed a sure base for future work which is now a part of daily psychiatric practice.

An issue that was already contentious a decade ago, remains an issue to this day: the question of the rotation of interns in psychiatry, and what constitutes adequate exposure to psychiatry. Various meetings have been held with the Health Professions Council of South Africa (HPCSA), but the issue remains unsatisfactory, especially considering the contribution of mental illnesses to the projected Global Burden of Disease.

During 2003, the infamous 'Act 90' was much talked about in SASOP, and meetings with industry commenced in an effort to pave the way for a mutually beneficial liaison with regards to the continued professional development (CPD) of psychiatrists. In March 2004, SASOP co-hosted the World Association of Social Psychiatry Congress in Johannesburg. During that year it had become apparent that patients were severely discriminated against in private practice as far as benefits were concerned, and SASOP, through the PPSA, had to fight earnestly against discrimination in terms of prescribed minimum benefits (PMBS). There were also serious problems related to establishing fees for service in the private sector, and it was evident that SASOP would need to become involved in this process.

Professor Merryl Vorster took over as SASOP president at the Drakensberg congress (themed 'the art and science of psychiatry') in September 2004. I worked with her as Honorary Secretary until 2006. Meetings were held regularly and became more streamlined. The MHCA was unexpectedly promulgated in December 2004, while most psychiatrists felt that the process had not received adequate consideration. The International College of NeuroPsychopharmacology (CINP) meeting in Cape Town in April 2005 provided an opportunity for SASOP to collaborate with an international body to host a congress. At a meeting of the SASOP National Executive during this congress, an important decision was taken to invest in a 'cost study' which would eventually result in sound compensation for practitioners in the private sector. There were several attempts to engage the HPCSA again to make the training of interns in psychiatry adequate. 
Professor Vorster focused on local issues in SASOP in 2005 - 2006 and paid attention to the needs of subgroups and special interest groups. The PPSA increased its profile in the urgent matters related to private psychiatry, and the State Employed Special Interest Group (SESIG) was focused on establishing a workable essential drug list (EDL). During 2006, the PPSA was renamed the 'P3 group' (Psychiatrists in Private Practice). It became increasingly evident during this time that the implementation of the MHCA was problematic, as reports started coming in from all corners of the country.

Dr Thabo Rangaka took over the reins of SASOP at the 2006 congress (themed 'facts and values in psychiatric practice'), held in Swaziland and organised by the Northern subgroup. This congress saw an attempt to apply the guidelines for sponsorship, albeit in a draft form. Dr Rangaka continued work along the issues overseen by Professor Vorster (e.g. internship and sponsorship guidelines), but also encouraged the development of young psychiatrists through a dedicated special interest group. By 2007 the developments in the South African Medical Association (SAMA) were such that it was clear that the interests of private psychiatrists would need to be re-organised. Consequently, the Psychiatry Management Group was constituted.

At the annual general meeting held during the Philosophy and Psychiatry Congress at Sun City in August 2007, the first edition of the African Journal of Psychiatry was released. It was also reported at the congress that the Eastern Cape Province was experiencing a crisis in the delivery of services to mentally ill patients. Dr Rangaka was instrumental in establishing a team that visited the region and started negotiations with the local Department of Health. He was a strong advocate for the necessity of addressing local issues via the local subgroups - at present, the local subgroup continues to wage a war for mental health in the province.

The process to register SASOP as a Section 21 company was finalised in 2008. Comments were received regarding the changing of SASOP's Constitution to align it with the Memorandum and Articles of Association governing a Section 21 company. At this time, work already performed on the establishment of SASOP treatment guidelines was being collated, as the need for such guidelines was becoming evident, particularly for practitioners in the private sector. The increasing use of generic medicine in psychiatry in South Africa prompted the establishment of a Generic Medicines Task Team towards the end of that same year.

My impression is that 2008 was a year in which SASOP changed significantly. It became apparent that a divide was developing between state-employed and private psychiatrists and that there was apathy at grassroots level, evidenced by poor attendance of subgroup meetings in various regions. The formal decision to change SASOP to a Section 21 company was made and this significantly changed the manner in which SASOP is run.
Dr Jan Chabalala took over as SASOP President at the congress in George in 2008, and the first meeting of the SASOP Board of Directors was held in October 2008. During Dr Chabalala's term of office, the 'new SASOP administration' had to find its feet and align itself with the requirements of a Section 21 company. At the same time, developments in SAMA led to the formation of the South African Private Practitioners Forum (SAPPF), which sought to represent the interests of most specialty groups in private medicine. The Psychiatry Management Group was formed and worked closely with SAPPF to address significant challenges such as the National Health Reference Price List (NHRPL). In retrospect, all of this activity on the front of private practice did seem to overshadow the needs and interests of state-employed psychiatrists.

In 2009, Drs Chabalala, Rangaka and I visited some of the subgroups to establish area-specific issues, being cognisant of the apparent rift that had developed in certain areas. To address the ongoing concerns regarding meeting sponsorship, the SASOP Benefit Fund was established. The aim was to provide sponsorship to those who were not able to secure funding in the system as it stood. Looking back, it was an ideal opportunity for SASOP to 'add value' to membership, but the intent has, at times, been misunderstood by members and pharma alike.

Disagreement regarding the proposed treatment guidelines emerged in 2008 and saw the appointment of the Treatment Guidelines Task Team in 2009, under the leadership of Professor Robin Emsley. Authors of the guidelines worked under his leadership for 3 years and the first draft was ready for comment in the second quarter of 2012. The fact that the guidelines have taken almost a decade to see the light of day is probably a reflection of the complex and different worlds in which state-employed and private practice psychiatrists find themselves.

In the years 2008 - 2010, SASOP confronted several issues, including the worldwide economic recession and its effects on pharmaceutical companies, and the potential requirement of the Society to have to submit tax returns. The guidelines for sponsorship were amended and refined and also applied to subsequent SASOPendorsed meetings, such as the national congress (themed 'mental health in Africa') in East London and the CINP Psychopharmacology workshops. Although criticised by some, these guidelines have generally been'a way forward'in an ever-changing climate of ethical practice in medicine.

In my term of office (2010 - 2012), I have sought to address the issues that I have seen develop in the preceding 8 years. The environment is certainly different to that of 2002, and the future is set to be even more challenging. I have focused on several areas, and have tried to tackle issues which will, in my opinion, be vital for us to survive as a profession in the years to come. These include the establishment of sound and operational subgroups; levelling the playfield for state and private psychiatrists as we are confronted 
with realities such as the proposed National Health Insurance (NHI); improving communication between the various groups within SASOP, as well as on the international arena; looking at ways of encouraging younger psychiatrists to become involved in SASOP; and refining and redefining our relationship with pharmaceutical companies, while ensuring that quality CPD events are accessible to most psychiatrists.

In conclusion, as SASOP celebrates its 60th anniversary and as I look back on the past decade, I would choose to take the optimistic view that, as South Africans with our pioneering spirit, we have shown what can be achieved and we can face challenges head-on. As individuals we may achieve a little, but as a Society we can achieve far more.

\section{Dr lan Westmore}

SASOP President, 2010-2012

SAfr J Psych 2012;18(3):72-74. DOI:10.7196/SAJP.380

74 SAJP - August 2012 Vol. 18 No. 3 